Methods This was a qualitative study, using questionnaires and semi-structured interviews. The population studied was ST4-6 Paediatric trainees in a single deanery. After questionnaire analysis a range of trainees were selected using purposeful sampling for more in-depth semi structured interviews. Thematic analysis was used for the analysis of interview transcripts and questionnaire responses.

Results Trainees valued some aspects of MSF, namely 1) the positive feedback it provides to trainees, 2) the opportunity for senior feedback and verbal discussion with supervisors. However all trainees felt that the full potential of MSF was not being fully realised, with concerns about 1) lack of meaningful feedback, 2) insufficient support to use feedback given, and 3) self-selection.

Conclusions The potential learning and development from MSF is not being optimised whilst it is in its current format. Trainees recognise the potential value of MSF, but at present the feedback is predominantly positive, and negative feedback received rarely translates into behavioural change. The need to end self-selection was repeatedly mentioned as crucial to encouraging the receipt of meaningful feedback, and the system needs to change to enable opportunities for giving and receiving meaningful feedback.

\section{G187(P) AIMING FOR THE APEX - REAL-TIME ASSESSMENT OF TEACHING USING MEDICAL STUDENTS IN A COMPULSORY, MULTI-STATION POSTGRADUATE ASSESSMENT TO ASSESS THE “DOES" AT THE TOP OF MILLER'S PYRAMID}

${ }^{1,2} \mathrm{~A}$ Reece, ${ }^{3,4} \mathrm{C}$ Fertleman. 'Department of Paediatrics, West Hertfordshire Hospitals NHS Trust, Watford General Hospital, Watford, UK; ${ }^{2}$ START Assessment Board, Royal College of Paediatrics and Child Health, London, UK; ${ }^{3}$ Department of Paediatrics, Whittington Health NHS Trust, The Whittington Hospital, London, UK; ${ }^{4}$ Whittington Campus, University College London, London, UK

\subsection{6/archdischild-2015-308599.181}

Aims The Royal College of Paediatrics and Child Health's (RCPCH) START assessment (Specialist Trainee Assessment of Readiness for Tenure) is a multi-station, scenario-based, formative assessment of consultant readiness. ${ }^{1}$ It is undertaken in the penultimate year of paediatric training and has been held 5 times since 2012. It consists of 12 scenarios (stations) mapping to the General Medical Council's Good Medical Practice domains. One of the areas assessed is teaching. We report an innovative scenario used in this assessment.

Methods To assess trainees at the top of Miller's pyramid ${ }^{2}$ the authors developed a novel station for the START assessment. The trainees were asked to prepare a micro-teach in the $4 \mathrm{~min}$ preparation time before the station which they then delivered during the $8 \mathrm{~min}$ station to two medical students who were in the first week of their paediatric attachment. Medical students were recruited from University College London Medical School. Topics related to general paediatrics. An assessor observed the teaching delivered by the trainee in the station. Feedback for this scenario and the whole assessment, benchmarked against described standards, is released some weeks later to the trainees' e-portfolio.

Results Thirty one medical students role-played across 3 sittings. Thirty (97\%) responded to a survey about their experience. The majority of students found the experience useful and enjoyable (Figure 1). Only 1 (3\%) student said they would not role-play for this assessment again. All replied they would, or may, recommend it to other medical students. Twenty five $(83 \%)$ wanted to be a paediatrician, 14 (37\%) had already decided before this role-play. Only $1(3 \%)$ medical student felt they should not have some part in feeding back to the trainees.

Conclusion Using medical students for a live teaching within a high-stakes, multi-station assessment is novel. It reaches the top of Miller's pyramid and maps to real life. The medical students who were taught found it worthwhile. For many of them it confirmed their desire to be a paediatrician (Figure 2).

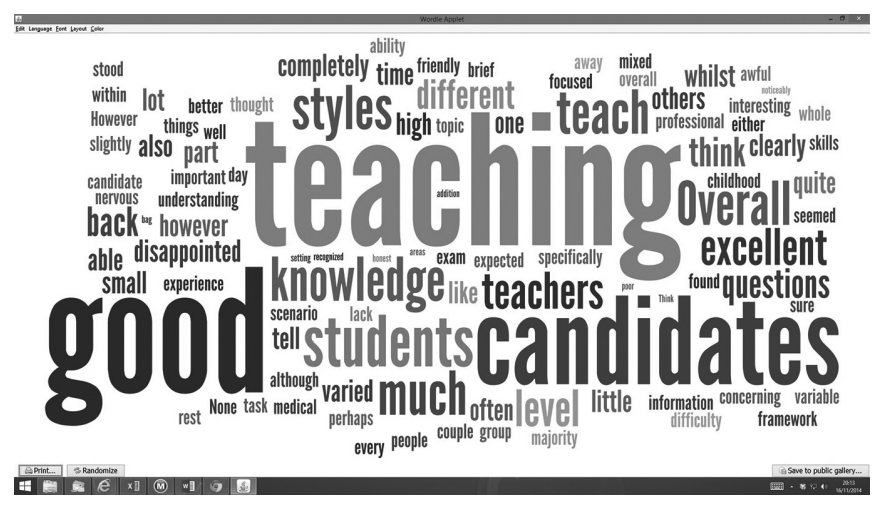

Abstract G187(P) Figure 2

\section{REFERENCES}

1 www.rcpch.ac.uk/start

2 Miller GE. The assessment of clinical skills/competence/performance. Acad Med. 1990:65(9):S64-S67

\section{G188(P) AIDING TRANSITION FROM ST3 - ST4 IN PAEDIATRIC TRAINEES. THE RESULTS OF A SURVEY OF BOTH TRAINEES AND TRAINERS}

1J Keene, ${ }^{2} \mathrm{C}$ Fertleman, ${ }^{2} \mathrm{~J}$ Moreiras. ${ }^{1}$ Department of Paediatric Hepatology, Kings College Hospital, London, UK; ${ }^{2}$ Department of Paediatrics, Whittington Health, London, UK

\subsection{6/archdischild-2015-308599.182}

Aim To assess how well prepared ST3 paediatric trainees felt they were prior to becoming middle grades. What steps had they taken to aid this and what measures had they felt could be

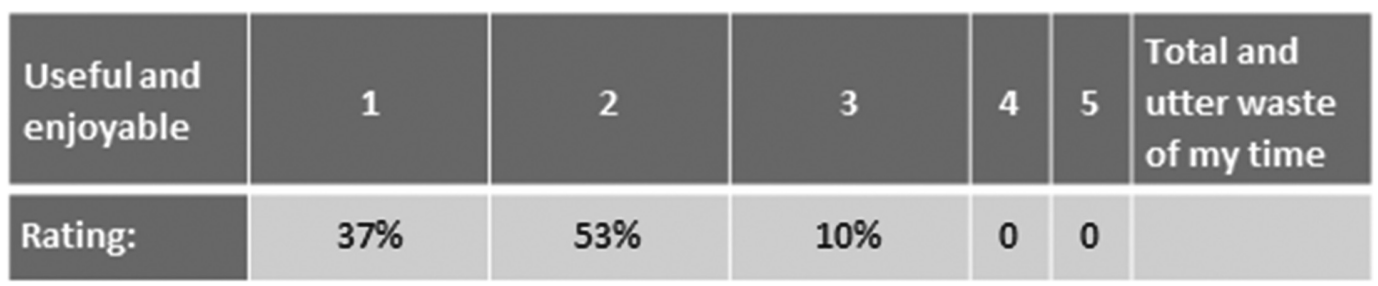

Abstract G187(P) Figure 1 Medical student responses to the question 'You kindly participated in the START assessment. What did you think of the experience?' 
implemented to increase preparedness? We compared their responses with a similar survey sent to consultant paediatricians responsible for their training.

Methods Mailshot with link to an online survey was mailed to all ST3 trainees in London and Eastern Deaneries. A further mailshot was sent to all college tutors for hospitals in the London Deanery. Trainees were emailed twice, in July 2012 and November 2013 meaning 2 different years of trainees were recruited. The college tutors were emailed just once in July 2012.

Results We received 73 trainee responses and 13 from consultants. ST3 trainees concerns were: 1) Concerns with leadership and decision making, 2) Night shifts without senior supervision, 3) Leading resuscitations, 4) Inability to perform procedures, (specifically neonatal intubation).

Most trainees felt they were not competent in dealing with common scenarios in community paediatrics, in particular safeguarding (69\%) and outpatients 66\%). They felt competent for general day-day work in general paediatrics (93\%) and neonates (93\%). The consultants felt trainees were lacking in their ability to run a neonatal resuscitation $(78 \%)$, had inadequate practical skills $(67 \%)$ and lacked in their leadership skills (56\%)

Acting up was identified as a way to better prepare trainees by both the trainees and trainers, however the majority of ST3s $(62 \%)$ had not acted-up as a registrar. Changes to current training with earlier exposure to child protection issues and extra time in neonates to improve procedural skills were also identified as ways to improve trainees' competence.

Conclusion Our data has identified specific areas where existing training could be altered or new training measures instigated to ensure that registrars feel better prepared for their new roles. Their concerns can be split into human and clinical factors. It is possible to address many of these issues in SHO years, making trainees more confident in leadership and delegation.

\section{G189(P) THE USE OF SIMULATION TO TEACH MEDICAL STUDENTS HOW TO RECOGNISE AND MANAGE A SICK CHILD - A CLUSTER RANDOMISED TRIAL}

${ }^{1} \mathrm{E}$ Harnik, ${ }^{1} \mathrm{~K}$ Mackay, ${ }^{2} \mathrm{H}$ Jacob, ${ }^{1} \mathrm{~B}$ Morrissey, ${ }^{1} \mathrm{~J}$ Moreiras. ${ }^{1}$ Paediatrics, Whittington Health, London, UK; ${ }^{2}$ Paediatrics, Barnet Hospital, London, UK

\subsection{6/archdischild-2015-308599.183}

Aims Many medical students lack confidence in their ability to recognise and manage acutely unwell patients, particularly children. With less time available for training and reduced exposure to sick children, simulation is being used effectively to develop technical and non-technical skills in postgraduate paediatric training.

Our aim was to evaluate the impact of a one-day paediatric simulation course on medical students' self-reported ability and confidence in recognising and managing sick children.

Method We conducted a cluster-randomised study of the impact of a novel undergraduate paediatric simulation course. All students undertaking their paediatric placement at a district general hospital over a six month period were invited to take part. Students were cluster randomised into the intervention (simulation) group or control group (standard paediatric attachment).

Students in the intervention group attended a one-day simulation course during the last week of their attachment. The course included clinical skills stations, a discussion on human factors, and five simulations of common paediatric emergencies, each followed by a structured debrief.
All participants completed a questionnaire at the end of their attachment and those in the intervention completed a further questionnaire after the simulation day.

The primary outcome measure was students' self-reported ability and confidence in recognising, assessing and managing sick children. The secondary outcome measured was their views on the course.

Results Sixty one students participated: 32 in the intervention group and 29 in the control group.

Self-assessed confidence in recognising a sick child was higher after the simulation course compared to controls (difference in confidence $0.75 / 5,95 \%$ CI $0.40-1.10, p=0.0002)$. Similarly, those in the intervention group were more confident in assessing and managing a sick child (difference in confidence 1.02/5, 95\% CI $0.74-1.31, \mathrm{p}<0.0001)$.

Six key themes were identified from the qualitative responses, including increased confidence in emergency situations and an appreciation of human factors. Students found the simulation useful and wanted it offered to all undergraduates during child health attachments.

Conclusion A one-day simulation course improves medical students' confidence in assessing and managing unwell children and is highly valued by students. Further studies are needed to evaluate its impact on clinical performance and confidence over time.

\section{G190(P) WHAT DO PAEDIATRICIANS AND GENERAL PRACTITIONERS THINK SHOULD BE INCLUDED IN THE UNDERGRADUATE PAEDIATRIC CURRICULUM?}

D Wylam, S Kempley, D Freeth. Medical Education, Barts and the London School of Medicine, London, UK

\subsection{6/archdischild-2015-308599.184}

Aims First presentations of paediatric illnesses normally occur in Primary Care, yet recent research from New Zealand (Pinnock and Jones, 2008) focused on hospital-based doctors' perspectives on what should be included in the undergraduate medical curriculum. Primary Care physicians may have different perspectives, which should also shape the education provided for medical students. This study aimed to elicit the opinions of both GPs and hospital-based paediatricians about the relative importance of various presentations and skills to the curriculum, while also establishing if there were any additional presentations or skills they felt should be added.

Method This questionnaire-based study in the UK replicated the NZ study of Pinnock and Jones by asking consultants in paediatrics to comment on the importance of their 25 paediatric presentations (e.g. a febrile infant, child with vomiting and/or diarrhoea). The study extended on the NZ study in two ways: by including General Practitioners (GPs) and by eliciting opinions on the degrees of competence in specific clinical skills that hospital paediatricians and GPs in the UK wish newly qualified doctors to possess.

Results Sixty-three responses were received and analysed (33 Paediatricians, 30 GPs). Results found an agreement between $\mathrm{NZ}$ and UK paediatricians as to the importance of the presentations provided, to the undergraduate curriculum $(69 \%$ or more answering very or quite important). In addition to the list provided, 12 suggested presentations were added. All the stated skills were also considered important to the curriculum, and 9 suggested additional skills were provided.

There was a statistically significant difference between the views of paediatricians and GPs as to the perceived importance of eight presentations and four skills. 